\title{
Academics' Narratives of Productive Learning Cultures During COVID-19 Emergency Remote Teaching in Australia
}

\author{
Marilyn Mitchell, Chelsea Gill and Sven Brodmerkel \\ Bond University, Australia
}

\begin{abstract}
This research applies sociocultural learning theory to describe the learning cultures that academics at a small Australian university cultivated during synchronous emergency remote teaching (ERT) at the start of the COVID-19 pandemic. We sought to understand how academics fostered learning when thrust into a new technological environment that required them to revise face-to-face teaching approaches while managing students' stress, anxiety, and expectations. The research combined a focus group with three small-group interviews. While the prospect of ERT initially concerned many participants, it generated growth in their teaching knowledge and ability. Our findings indicate that the assumptions of sociocultural learning theory provide helpful bases and practical ideas upon which academics can plan and deliver teaching to cultivate productive learning cultures during crises that require remote teaching.
\end{abstract}

Keywords: Emergency remote teaching; COVID-19 teaching; productive learning cultures; sociocultural learning theory.

\section{Introduction}

This research adopts a sociocultural perspective to explore the learning cultures of emergency remote teaching (ERT) at a small Australian university during the COVID-19 pandemic when face-to-face classes were halted for one trimester. As defined by Sagy et al. (2018), a learning culture consists of "the beliefs, values, and behaviors a person or a group of people have with regard to their own 'learning' in specific contexts" (p. 418), and a productive learning culture is one in which students drive their own learning. Our primary question was how academics fostered learning during ERT. Sociocultural theory is appropriate for this question as it explains that learning is "a fundamentally social and cultural activity" and "cannot be understood apart from its historical, cultural, and institutional contexts" (Lattuca, 2002, p. 713).

As Rapanta et al. (2020, p. 941) note, "the worst thing that could happen is not learning from the crisis we experienced." This research contributes to knowledge of pedagogical practice and student success by considering how the context of the pandemic affected teaching and learning at a university that has traditionally had a strong focus on face-to-face education. While the prospect of ERT was initially concerning, it generated remarkable growth in participants' teaching knowledge and ability as they were forced to revise face-to-face approaches to engage students as well as manage students' stress, anxiety, and expectations in a new technological environment. Our findings indicate that the first two assumptions of sociocultural learning theory provide a helpful foundation upon which academics can plan and deliver teaching to cultivate productive learning cultures during crises that require remote teaching. 


\section{Defining Emergency Remote Teaching (ERT)}

According to Hodges et al. (2020), ERT differs from online teaching as it is "a temporary shift of instructional delivery to an alternate delivery mode due to crisis circumstances" (para.13). Key differences between the modes are subject to support available to develop a course, and lecturers' knowledge of online teaching technology as well as knowledge of and ability to apply online instructional design processes. Many lecturers engaging in ERT had to move their classes online overnight without a high level of support and began teaching remotely with no break.

\section{Background}

Bond University is a small private Australian university that operates with a three-semester-per-year timetable (trimesters). In March 2020, when higher education institutions around the world closed in-person classes and shifted to ERT, Bond was in the ninth week of its 12-week January trimester. At this time, the University's Office of Learning and Teaching (OLT) trained lecturers on using Blackboard Collaborate to deliver ERT. Two weeks later, lecturers taught through Collaborate from their classrooms. All classes were delivered synchronously through ERT in the May trimester.

\section{Literature Review}

In conducting this review, we found no research specifically about the classroom cultures of synchronous ERT and no research that applied sociocultural learning theory to ERT. Most research about ERT reflected upon universities' institutional responses and how universities could or should change post-pandemic (e.g., Kift et al., 2021). Much research also provided personal reflections on working at a university during the pandemic (e.g., Leask, 2020), and some research presented ERT best practice (e.g., TEQSA, 2020). Nonetheless, we found six studies that contained limited descriptions of how sociocultural aspects of classroom teaching changed. The changes described were from the perspectives of students (Harris et al., 2021), academics (Bhagat \& Kim, 2020; Jung et al., 2021; Watermeyer et al., 2020; Yang \& Huang, 2021) and institutional leaders (de Boer, 2021).

Together, the six studies noted both positive and negative changes to learning cultures as well as changes in lecturer-student interaction outside the classroom. The three studies that discussed synchronous ERT (Harris et al., 2021; Jung et al., 2021; Yang \& Huang, 2021;) described mostly positive changes while the other three studies described mostly negative changes. Only one study (Watermeyer et al., 2020) discussed changes outside the classroom. Starting with the positive changes, Harris et al.'s (2021) study described a teaching situation like ours in which the lecturers used online learning tools to interactively engage students. These researchers conducted a qualitative survey of students in a single ERT subject. Students reported that the "live" lectures instilled a feeling of togetherness and being in a normal classroom and that the online tools (e.g., polls, the chat, breakout groups) were engaging. The researchers noted that the students' comments emphasised the social nature of learning. The studies by Yan and Huang (2021) and Jung et al. (2021) also noted a positive change in learning cultures, which was that teacher-student interaction increased due to use of a chat protocol. Moving to the negative changes, Watermeyer et al.'s (2020) survey of 1148 academics in the UK found that for most "respondents, a move to online [learning, teaching, and assessment] ... was viewed negatively and based on a view that their pedagogical praxis had been reduced to the fulfilment of rudimentary technical functions" (p. 631). Next, U.S. researchers Bhagat and Kim (2020) noted that student engagement decreased during ERT. These researchers said that "educators are ... facing difficulties in maintaining the same level of student engagement ... as in a regular face-to-face scenario" (p. 369). Finally, a 2020 survey of institutional leaders by the Dutch Inspectorate of Education (de Boer, 2021) found that "[o]nline education was 'more compressed'; [that there were] shorter lectures, fewer questions from students in between, and 'difficult' interaction between teacher and student" (p. 102). This response points to reduced student engagement. While de Boer said that the "picture was (moderately) positive ... reports appeared in the media that students felt ... the online education ... was substandard" (p. 102). Regarding changes in lecturerstudent interaction outside the classroom, Watermeyer et al. (2020) found that many academics gave more individual consultations and increased pastoral care during ERT to help students deal with their mental health.

As mentioned, none of the reviewed studies focussed specifically on learning cultures and none applied sociocultural learning theory to understand how learning cultures changed during the pandemic. Therefore, the published research creates an opportunity for studying the learning cultures of synchronous ERT classrooms from lecturers' perspectives using sociocultural learning theory. Our research focuses on how lecturers adapted their teaching to cultivate productive learning cultures during synchronous ERT. Sociocultural learning theory, which is described below, is an appropriate theory for studying synchronous ERT as researchers have previously used it to study online learning (e.g., Meskill, 2013). 


\section{Theoretical Framework}

This research applies sociocultural theory as described by Meskill (2013), who said that "[a] sociocultural perspective sees all human psychological processes as social in nature, human development (learning) as emerging through social experience and language as the essential tool for development" (p. 2). The six assumptions of the sociocultural approach (figure 1) are: (1) learners have agency, (2) the environment and the individuals within it mutually affect individuals' learning, (3) more skilful others influence learning, (4) individuals in learning environments appropriate social practices to develop expertise, (5) individuals learn by verbalising their thoughts with others, and (6) individuals exist in a state of continuous learning (Meskill, 2013).

\section{Figure 1}

Six Assumptions of Sociocultural Learning Theory (based upon Meskill, 2013)

1. Learners have agency

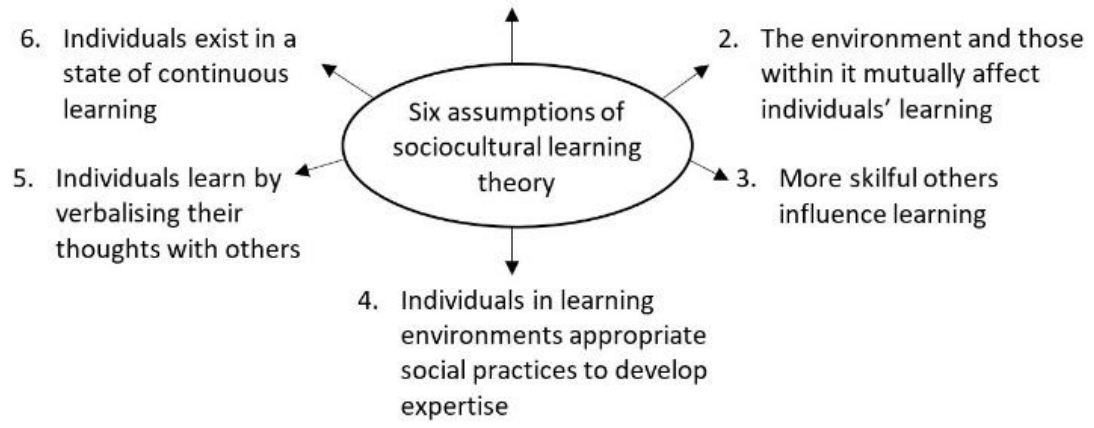

Regarding assumption (1): Since learners have agency regarding what and how they learn, lecturers should realise that learners will make their own choices regarding ERT. Therefore, lecturers should discover what works for students in ERT classes and adjust teaching as appropriate. Assumption (2): Lecturers need to understand that the ERT culture that they and their students cultivate will affect everyone's learning. Therefore, it is incumbent upon lecturers to try to cultivate an inclusive environment, realise that the disruption of the pandemic is likely to affect students and their learning, and determine how to keep students engaged. Assumption (3): Since students learn from those who know and can do more, lecturers need to discover ways in ERT for students to learn from one another. Assumption (4): Students learn social practices as part of their study, hence lecturers need to find ways to model these practices and have students practice them in ERT environments. Assumption (5): Students learn by verbalising their ideas, so lecturers need to invent ways for all students to share their ideas in ERT. Assumption (6): Because students are learning all the time, lecturers should develop ways for students to engage with subject concepts outside of the ERT class. Our research focussed on the first two assumptions of sociocultural learning theory since academics had greater control over them than over the other assumptions. That is, academics could have some control over practices used for student engagement and practices for fostering a productive learning environment. From the first two assumptions, we developed three research questions as follows. RQ1 aligns with the first assumption while RQ2 and RQ3 align with the second assumption of sociocultural learning theory:

- RQ1. What were academics' expectations of ERT and how did they plan for it?

- RQ2. How did academics present themselves and manage boundaries during ERT?

- RQ3. How did academics implement and practice ERT?

\section{Method}

To gather rich, detailed descriptions to answer the three research questions, the qualitative approach of a focus group and small group interviews was chosen. This choice enabled an efficient and economical approach to collecting data and gaining deep insights which would emerge from the interactions of participants that may not be uncovered using other methods (Duggleby, 
2005). Semi-structured questions were designed so as to probe more deeply into participants' responses to gain as much detail as possible and allow participants to develop personal narratives around the research questions.

From the first assumption of sociocultural learning theory, that learners have agency, the following questions were developed to understand how academics planned for and felt about teaching in this new environment knowing that it might not be suitable for all students.

\section{Questions for RQ1: What were academics' expectations of ERT and how did they plan for it?}

1. What was your level of familiarity or previous experience with online learning and teaching when the pandemic began, and you first started teaching remotely?

2. How confident did you feel about remote teaching when the pandemic began?

3. What emotions did you feel?

4. How did the pandemic affect your thoughts about your students and their learning?

5. What do you believe are general characteristics of productive learning cultures?

6. Do you think that you were able to create a productive learning culture in remote teaching? How so?

\section{Questions for RQ2: How did academics present themselves and manage boundaries during ERT?}

1. What strategies did you use for making yourself 'visible' as a person online?

2. How was remote teaching different than face-to-face teaching?

3. What were the 'boundaries of online intimacy'?

4. How were these boundaries managed?

\section{Questions for RQ3: How did academics implement and practice ERT?}

1. What engagement or interaction strategies did you use?

2. How did you address, manage, and mediate cultural or cognitive diversity?

3. How did you manage different levels of knowledge?

4. What norms or practices of interaction evolved in practice?

Participants were recruited via flyers distributed to academics' mailboxes across all faculties and an advertisement in the staff newsletter. In total, 15 academics representing most faculties gave informed consent to participate. All focus groups and interviews, which lasted 60 minutes on average, were audio-recorded and transcribed. To protect their identities, participants were given pseudonyms.

Among the participants, three (Rafael, Mike, and Warren) were already very experienced with ERT when the pandemic began. Another three (Ivy, Glen, and Darius) had some experience, and eight (Amy, Mara, Sue, Gina, Jane, Mai, Owen, and Carl) had no experience. One participant (Brad) did not respond.

The data analysis followed the three-stage process suggested by Miles and Huberman (1994): (1) data reduction, (2) data display and, (3) conclusion drawing and verification. First, meaningful chunks of information were identified and developed independently into initial coding themes. In the second stage, we discussed the initial categories and collaboratively reviewed the inferences drawn, resolving differences in classification and interpretation by means of a "negotiated agreement" in which we presented our individual justifications for certain categorisations and then discussed them until we achieved consensus (Campbell et al., 2013, p. 305). In the data analysis stage, conclusions were drawn based on the emerging conceptual themes and in relation to the chosen theoretical framework. 


\section{Results}

This section presents participants' responses organised into themes arising from the three key question areas. Figure 2 provides a summary of the themes emerging from the research questions.

\section{Figure 2}

\section{Themes Emerging from the Three Research Questions}
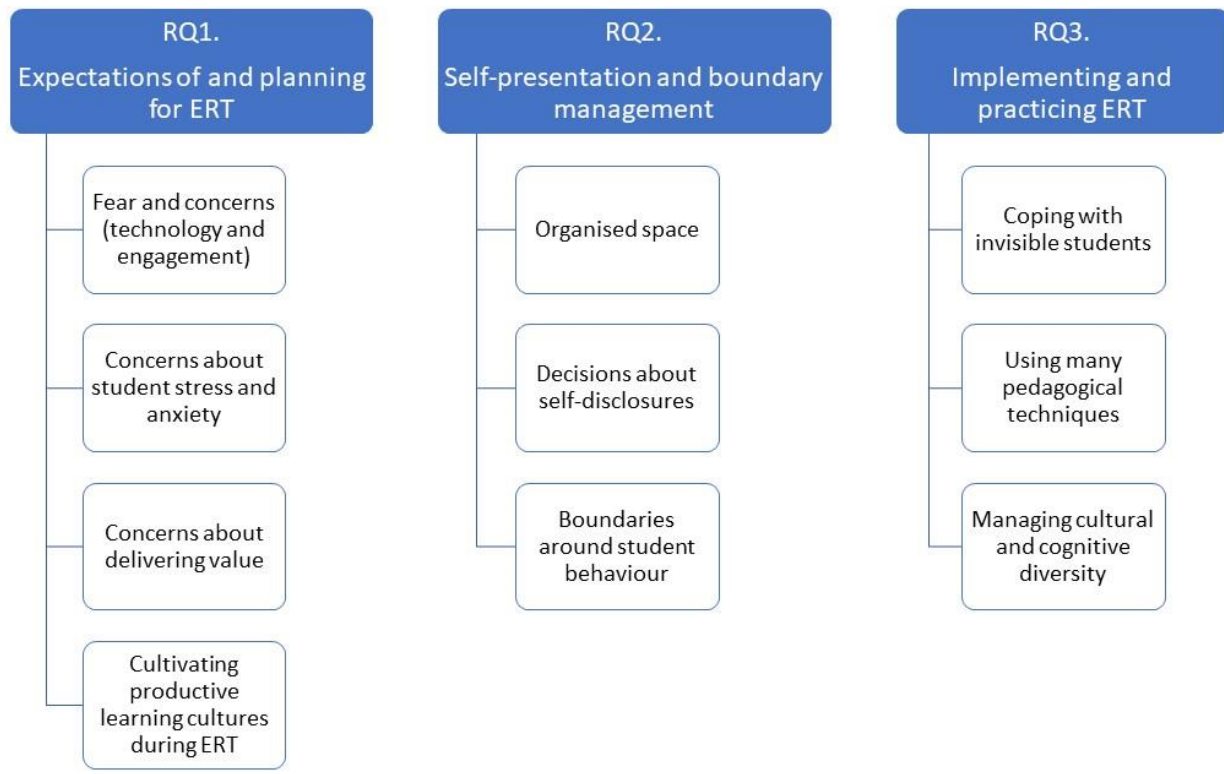

\section{Expectations of and Planning for ERT}

In the first section of the interviews, participants were asked about their confidence and emotions when starting ERT and their thoughts about student learning. We also inquired what makes a productive learning culture and whether they were able to achieve one in ERT.

\section{Fears and Concerns.}

Nine participants expressed fears and concerns about using the technology and keeping the students engaged. Regarding the technology, Mai said that she was "nervous" when she started the May trimester despite "finessing [Collaborate] and ... other [technical] things." Jane was also concerned about the technology, saying, "The only thing that worried me was being proficient at doing things quickly and not stumbling." Owen expressed concerns about "the stability of the Internet." Sue was apprehensive about using the technology and engaging students. Sue added she was feeling "very nervous" about the technology and was concerned about keeping the same "intimate" connection with the students that she typically experienced. Ivy was particularly worried about engaging new students during ERT: "Going into the May [trimester] ... was ... daunting, having a ... new group of students, not knowing them at all."

Despite initial concerns, three participants developed positive thoughts about online teaching. Owen was pleasantly surprised with student participation in the chat. Carl's initial anxiety about the technology changed: "I actually quite enjoyed it. It was ... stimulating to teach in this ... environment." Mara found benefits in delivering material online and expressed that she did not want to return to all face-to-face teaching: "I don't want it to be all face-to-face. Some things like the ... pure lecture, content stuff, is dead."

Jane and Amy negotiated their fears of the technology by asking their students for help:

I ... positioned it ... early on saying, 'This is completely new for me. So, it might sometimes take me a little while to ... share screens and put you into breakout groups'... I just asked them if I didn't know, and they quite liked having that role. (Jane) 
I had the expectation that they would be young ... [and] into this remote ... No. They were so uncomfortable... We ended up having some ... good discussions about it when I admitted my stage fright. It probably wasn't until about week three that we were able to be ... open and say, look, how are you ... feeling because I'm not really enjoying this. How can we make it better? (Amy)

\section{Concerns About Student Stress and Anxiety.}

Five participants mentioned concerns about student stress and anxiety. They dealt with these issues by staying mindful of students' feelings and potential situations, talking about the pandemic during classes, having individual meetings, frequently checking in, and putting greater emphasis on community building.

For example, Darius assumed that his students would want to talk about the pandemic, so he re-designed his course around it:

To get where students were at, we designed ... activities around ... aspects of living through a pandemic... There were students ... from Canada, Oman, Europe, Asia, [so] you could get a real ... update with people talking... 'This is what's happening here, this is the stage of lockdown we're at'... But also, [I learned] how much it did occupy students' lives.

Mai thought that the uncertainty of the pandemic caused her students to feel anxious and stressed so she arranged additional individual online-meetings. Jane also thought that her students were more stressed than usual so she frequently "checked-in" with them and worked on building community. She said, "We did a lot of check-ins ... We would kick off with, 'How're you going in your country? What lockdown are you in?' I do think that helped build community online... we're all in it together kind of thing."

Concerns About Delivering Value.

Mike and Amy expressed concerns about delivering value to students during ERT. Mike was concerned about losses associated with students not being on campus:

[The students] normally get ... huge benefits from being on campus ... That's the ultimate when you see them still connecting with their classmates [online] because we know that just producing content and having it online [won't] ... sell... Because the things that people are ... paying for are much more about that personal connection to your teacher and ... classmates.

Amy continually sought feedback from her students:

[I wanted the classes] to be a good experience ... and not making it feel like it was just a ... second-rate thing because this is what the pandemic's dished up... at the end of each session, we'd ... go around and say, ... 'We've spent two hours together. Did you get value for your time? If not, what would you change?

\section{Cultivating Productive Learning Cultures During ERT.}

When asked about the characteristics of productive learning cultures and whether these developed during ERT, most participants noted the need for students to engage with the content and interact. Some participants went further to say that in productive learning environments, students take control of learning, teach one another, learn together, and create a democracy for all students to share ideas.

Rafael described a productive learning culture as an "environment where people want to go to learn" and where students take "control of their own learning environment." Mara said that peer learning and teaching constitute a productive learning culture.

Darius said that in a productive learning culture students can safely share their opinions:

... in a way that ... promote[s] growth... I thought that the online environment is ... a ... great place for that, and that there is a kind of democracy with the chat feature that nobody's louder than anybody else... Also, students with English as a second language, who might otherwise remain silent and need an extra second for permission to voice, were ... very engaged in chat discussions.

Owen said that a productive learning culture is one in which there is "a lot of student interaction, which is either with [the teacher or] ... the content... [It is] to be engaged with the material, that they can see value... in it."

Mai said, "a big part of ... [a productive learning culture is] ... interaction ... so you get some feedback on how it's going ... What I think is productive is that engagement and that interaction." Ivy also stressed the importance of engagement "because ... if I was a student, I wouldn't be able to sit in front of the computer and watch a class for two hours." 
Jane said that a productive learning culture is one in which all students contribute. She said, "I make sure that in each class there is one point where we go around the room and ask everyone's view on something."

\section{Self-Presentation and Boundary-Setting}

This section discusses how participants organized their ERT space, made decisions about self-disclosures, and set boundaries on student behaviour.

When asked "How did you make yourself visible to your students?", participants discussed the physical spaces they prepared for ERT, the personal information they shared, and their dress. Only one participant, Rafael, aimed to make students feel physically closer to him by sharing a greater view of himself at home:

To show them that ... we're people, we'd walk around with a video on an iPhone, and we'd stream [it and] ... say ... 'While we're having a break, this is what we do'... And we walked into the kitchen and made a ... coffee... So, we ... tried ... just constantly [to] show different faces of ourselves.

In contrast, four participants discussed how they limited students' views of their homes. For example, Gina discussed how she organised a neutral-looking space:

I had kind of an office... I was ... marking in my living room. So [with ERT], ... I ... made my office with ... books at the back, then windows [which] are kind of neutral, but [the view was] kind of the same [that] they would see me in a classroom ... But [also]..., showing some things about yourself in a ... bit more personal [way], having the dogs barking from time to time, so sharing your pet stories or whatever you can't control.

Warren was mainly concerned about family interruptions: "I've seen a few videos when the COVID started about families passing behind the screen, so... I told my wife to go to the shopping mall or something during that time."

Darius was concerned about dressing for work and play at the same time, looking credible, having students easily see and hear him, and preventing his children from interrupting:

I dressed the top half for work. I had my shorts on ready ... to play outside with the kids ... afterwards. ... I didn't ... [already] have the space [set up] ... I painted my garage wall and bought a bookshelf ... and made a desk out of ... planks of wood ... I ... got ... extra lights. I got a ... good microphone ... and I sorted out making a space where it looked like I was somebody who could talk on these things... The challenge of creating that online presence was ... how to NOT have the kids running in.

When asked about whether and how they disclosed personal information, participants expressed different ideas. Firstly, Ivy and Mara said that they did the same thing as during face-to-face teaching. In contrast, Jane invited students to participate with her in short personal activities: "We did ... things like meet each other's pets... then someone wanted to have hat day ... We did ... things like that just to try and break down barriers and have a nice time."

While Brad discussed his family and showed a family picture, Mai said that she would not discuss her family because she wanted to keep professional boundaries with students.

Owen reported that he disclosed less about himself in ERT: "I was revealing ... more in those ... face-to-face lectures, but online when there is a break, the mic and camera are off, go get a coffee, come back, ... click the button, and it's on again."

As most of the participants were new to teaching online, knowing what boundaries to set and enforcing them was sometimes tricky, and different participants set more open or closed boundaries. Five participants set explicit rules around appearance, behaviour, and communication. To begin, Amy and her students set ERT boundaries together: "We set ... what we ... expected and made the point that although we're engaging remotely, you need to think of this as still being in a more formal setting... Having ... [boundaries] as group norms ... protected everybody."

Mara set rules about appearance and behaviour, telling students: “This [remote class] is just like any other session: you don't wear a onesie, you don't eat, speak with your mouth full." 
Rafael discussed setting boundaries around communicating professionally:

Whilst we had fun, we were still ... formal... We talked about professionalism ... and our roles and responsibilities... Within the first week, ... we dropped the hammer pretty hard. If ... anything [was] starting to ... push past those boundaries like inappropriate comments, it would be, 'That is inappropriate, not an appropriate comment for the forum we're in'...

Mike set rules around which communication channels students should use with him:

You set the protocol at the start ... and ... while you use different tools to connect with people online, ... you manage which channels you're ... going to offer ... So, [if] students want to contact you personally, then they need to do it through your work email.

Sue set boundaries at the start of her course: "You set the ground rules ... early. They knew that I was going to ask [random] questions. I made it ... clear if you need to go to the bathroom or ... whatever, just click 'Away'."

Jane and Carl had students who did not fully cooperate with rules set for camera use. Jane said, "Sometimes people wouldn't share video because they were either in their pyjamas or they had no makeup on, and that does challenge ... community building."

Carl said, "I felt that it [camera use] was a boundary, and I couldn't get beyond it... it's crucial for us, it's teamwork... Four of five people ... have their cameras on, and one just refuses."

Gina allowed her students to eat during class as the subject ran during the local dinner time, and she wanted them to feel comfortable: "They were eating... [It was] kind of like ... 'I'm at home. Let's be comfy and have dinner'. Have dinner at the time when I'm teaching."

Darius removed a student from the first ERT lesson for crossing boundaries:

In the first class ... I ejected someone... They were using the chat feature to make derogatory comments about ... other people in the room... So, I made an explicit comment on what the boundaries were, ... and he posted a picture of a crying face emoticon, and I immediately pressed eject ... I waited five seconds and said to one hundred and twenty-odd students, ... 'So, if you didn't realize, I just ejected that person from the room... I'm going to follow up with them ... What happened wasn't okay'. [My action] created a very nice place for other people... It's safe.

\section{Encouraging Engagement and Interaction}

All participants expressed concerns about and developed strategies for encouraging students to engage and interact in ERT. The main issues were not seeing students' faces in class and keeping students attentive and interacting. As special attention needs to be given to those students who are culturally or cognitively diverse, this section of the interviews also asked about engagement and interaction strategies used for such students.

Coping With Invisible Students.

As several participants noted, they missed seeing students' faces during teaching. To help overcome this problem, Rafael asked all students to upload their photos into Collaborate. Owen noted that monitoring students' interest in the subject was difficult: "That's ... harder with the online model because you cannot see their faces... I think that's the biggest difficulty, how to gauge their alertness." Mara overcame the problem of not seeing faces by communicating a great deal in the chat. She said, "[interaction] just happens in the chat. But you learn to talk with them. You talk and write quite a lot."

Using Many Pedagogical Techniques.

Four participants discussed different pedagogical techniques used to encourage engagement and interaction. Firstly, Rafael said that he designed his ERT class to get students "to engage in a fun, interactive way." For example, he set up different weekly competitions in the discussion board, such as "If you were a [name of a profession], given a superpower, what would your superpower be?" Regarding this approach, Rafael said, "They actually ended up taking control of their own learning environment." To measure whether students were engaging, Rafael ran a survey and then adjusted his teaching.

Gina engaged her students both in and out of her class by asking students to watch about ten minutes of video prior to class. She reported that her class became "very active" as they could then discuss the material. 
Next, Mai regularly sought feedback using emojis: "I ... put up ... tons of different emojis and got people to circle how they were feeling." Mai also said that she used many different platforms to "do something different" to keep her students engaged. Jane discussed how she changed activities at least every 20 minutes: "I would teach maximum 20 minutes before we did ... something."

\section{Managing Cultural and Cognitive Diversity.}

To better understand engagement strategies, participants were asked how they managed cultural and cognitive diversity during ERT. Participants discussed ways in which they managed diversity as they defined it. Mike described how he engaged students who had different communication preferences:

I see it as managing different modes of ... participation ... like verbal or written and synchronous and asynchronous... Some students ... will be happy to jump on a ... video and respond ... live... Others will be much more comfortable writing comments on an online forum. So, I use ... tools that let people review content or interactions ... and respond [to them] in their own time ... It's ... helped a lot with the students where English might not be as strong.

Rafael discussed ERT participation challenges with students from China:

The two Chinese students ... were ... quiet... We had a look at their ... log times. They were on for the whole session, but ... they wouldn't comment... Trying to ... engage with them was ... difficult... So, we ... created small breakout groups where... they'd only engage with three or four other people.

Rafael, Sue, and Carl managed cultural diversity by including information or questions about different countries. Rafael said:

The ... first discussion board competition was ... [about cultural diversity]. It was what are the roles and names of [a particular profession] from around the world, and what are their capabilities and responsibilities? ... How did they approach problems? What was their scope? ... [The students] ... highlighted there is ... huge cultural difference and to be accepting of that.

Next, Mai saw diversity in different students' needs or abilities to participate. She devised a way to give those who participated less a chance to speak:

On Collaborate, I said, 'Okay, everyone, hands up [using the icon]. You can put your hand down when you give me an answer' ... I did it as soon as that awkward silence was happening, and it was something that I knew ... they could respond to. I would do that because you ... have people who respond all the time, and it's always a challenge to not have to rely on them ... but to give other people a chance ... [and] encourage [them].

Finally, Darius said that he provided diverse learners with different types of materials: "For every bit of content, we have something visual, ... textural, and something to listen to ... for different cognitive abilities."

\section{Discussion}

This section will discuss practical ideas for cultivating productive learning cultures during ERT as based upon the results and considering the literature reviewed and the first two assumptions of sociocultural learning theory. Table 1 summarises the practical ideas found through this research. 


\section{Table 1}

Practical Ideas for Delivering ERT

\begin{tabular}{|c|c|c|c|c|c|}
\hline Questions & \multicolumn{5}{|c|}{ Themes and practical ideas } \\
\hline & Prepare & $\begin{array}{l}\text { At the start of } \\
\text { teaching }\end{array}$ & $\begin{array}{l}\text { Remain mindful } \\
\text { of students, } \\
\text { stress and } \\
\text { anxiety }\end{array}$ & $\begin{array}{l}\text { Aim to deliver } \\
\text { value }\end{array}$ & $\begin{array}{l}\text { Aim to foster a } \\
\text { productive } \\
\text { learning } \\
\text { environment }\end{array}$ \\
\hline $\begin{array}{c}\text { RQ1. } \\
\text { Planning ERT }\end{array}$ & $\begin{array}{l}\text { Practice with the } \\
\text { technology. }\end{array}$ & $\begin{array}{l}\text { Be transparent that } \\
\text { you are a novice in } \\
\text { delivering classes } \\
\text { online. } \\
\text { Enlist students' } \\
\text { help with the } \\
\text { technology as } \\
\text { required. }\end{array}$ & $\begin{array}{l}\text { Realise that } \\
\text { students are } \\
\text { concerned about the } \\
\text { situation. } \\
\text { Regularly ask } \\
\text { students what is } \\
\text { happening and how } \\
\text { they are coping. } \\
\text { Set additional } \\
\text { individual meetings } \\
\text { to help students } \\
\text { cope and learn. } \\
\text { Redesign lessons to } \\
\text { incorporate aspects } \\
\text { of the crisis. }\end{array}$ & $\begin{array}{l}\text { Seek feedback from } \\
\text { the students on } \\
\text { what is working } \\
\text { well and what } \\
\text { needs } \\
\text { improvement. } \\
\text { Realise that many } \\
\text { students are losing } \\
\text { the university } \\
\text { experience that } \\
\text { they wanted, which } \\
\text { partly included } \\
\text { personal } \\
\text { connection to you } \\
\text { and classmates. } \\
\text { Use break-out } \\
\text { groups to help } \\
\text { students connect. } \\
\text { Organise virtual } \\
\text { places for students } \\
\text { to meet outside } \\
\text { class. }\end{array}$ & $\begin{array}{l}\text { Develop an } \\
\text { environment in } \\
\text { which it is safe for } \\
\text { all students to share } \\
\text { ideas and teach one } \\
\text { another. } \\
\text { Encourage } \\
\text { contributions and } \\
\text { interaction. } \\
\text { At least once } \\
\text { during each class, } \\
\text { ask all students for } \\
\text { their views. }\end{array}$ \\
\hline & $\begin{array}{l}\text { Organise your } \\
\text { space }\end{array}$ & $\begin{array}{l}\text { Decide what to } \\
\text { disclose about } \\
\text { yourself }\end{array}$ & $\begin{array}{l}\text { Set boundaries } \\
\text { around student } \\
\text { communication }\end{array}$ & & \\
\hline $\begin{array}{l}\text { RQ2. } \\
\text { Presenting } \\
\text { oneself and } \\
\text { managing } \\
\text { boundaries }\end{array}$ & $\begin{array}{l}\text { Help students to feel } \\
\text { physically closer to } \\
\text { you by showing part } \\
\text { of your home or } \\
\text { teaching space. } \\
\text { Show something } \\
\text { personal about } \\
\text { yourself such as a } \\
\text { pet. } \\
\text { Create a space in } \\
\text { which you look } \\
\text { credible as an } \\
\text { academic. } \\
\text { Limit the potential } \\
\text { for family } \\
\text { interruptions. }\end{array}$ & $\begin{array}{l}\text { Remain } \\
\text { professional } \\
\text { according to what } \\
\text { professional means } \\
\text { to you. }\end{array}$ & $\begin{array}{l}\text { At the start of a } \\
\text { subject, discuss } \\
\text { boundaries with } \\
\text { students. } \\
\text { Discuss the } \\
\text { channels through } \\
\text { which students } \\
\text { should } \\
\text { communicate with } \\
\text { you. } \\
\text { Set expectations for } \\
\text { camera and audio } \\
\text { use. }\end{array}$ & & \\
\hline
\end{tabular}




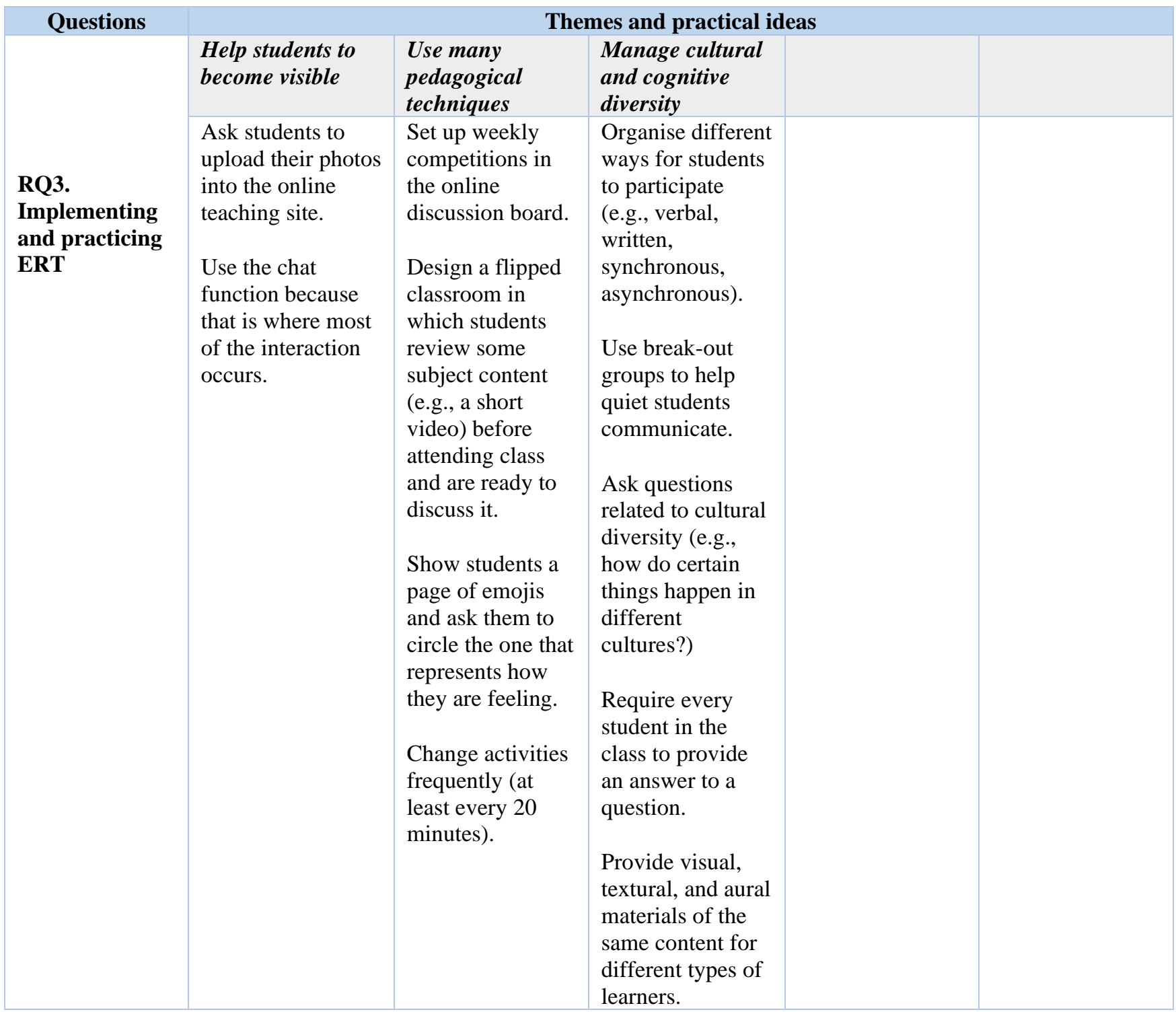

Our findings had some similarities to those found in the literature review. Like the Harris et al. (2021), Yang and Huang (2021), and Jung et al. (2021) studies, our research found that the chat function was particularly helpful for interactively engaging students during synchronous ERT. As one of our participants noted, the chat takes the place of seeing students in a face-to-face classroom. That is, the chat helps make students "visible" and is the primary channel through which academics can sense the attention levels of students. Also like the Harris et al. (2021) study, our research noted that academics used a range of online tools such as breakout groups to help students interact with the content as well as one another. Further, like respondents in the Watermeyer et al. (2020) study, our participants said that they gave more individual consultations during ERT to help students cope with stress and anxiety.

Considering our findings through the lens of the first assumption of sociocultural learning theory, that learners have agency, many of our participants discussed ways in which they tried to meet individual students' needs so that the students would remain in class and continue learning. Although the participants clearly made some assumptions about the students' needs (e.g., that the pandemic was of concern to the students and they needed to discuss it), two participants sought feedback from their students on how to make ERT better. One participant ran regular surveys and the other engaged students in open discussion. Therefore, an important step that academics can take in following the assumption that learners have agency is to keep communication with students open and give them a voice in how classes are designed and delivered. 
Considering our findings through the lens of the second assumption of sociocultural learning theory, that the environment and those within it mutually affect individuals' learning, many of our participants assumed that their students would want to: (1) get to know them as people, (2) have clear and fair expectations about communication and classroom behaviour, (3) get to know their classmates, (4) have an interesting learning experience, and (5) have their individual learning needs met. Some of our participants described ways in which they tried to help their students feel closer to them to create a more open learning environment. For example, our participants showed students their pet, part of their home, or a photo of their family. To create an environment that was safe and inclusive for all students, some participants set classroom boundaries for communication and behaviour together with their students. Next, to help students get to know their classmates, participants used the chat and breakout groups during classes. Some participants also created virtual areas and discussion boards in which students could interact at any time. To make the learning more interesting, participants designed many types of activities in which they invited students to engage both inside and outside the class (e.g., using a flipped classroom). Finally, to manage cultural and cognitive diversity, participants organised different ways in which students could participate in class (e.g., synchronously, asynchronously), discussed cultural diversity, provided learning materials in different formats (e.g., written, visual), and found ways to get all students to participate.

\section{Conclusion}

The intent of our research was to study the learning cultures of synchronous ERT classrooms at the start of the COVID-19 pandemic from lecturers' perspectives using the first two assumptions of Meskill's (2013) sociocultural learning theory. These assumptions are that learners have agency and that the environment and those within it mutually affect individuals' learning. No other research took this approach. Our inquiry indicates that these assumptions provide helpful bases and practical ideas upon which academics can plan and deliver ERT to cultivate productive learning cultures. This research delivers practical ideas on planning for ERT, presenting oneself and managing boundaries with students, and implementing and practicing ERT. Limitations of the study were the small number of participants as well as lack of research on students' perspectives. Participants' reactions to ERT were positive overall, and thus individuals in this group most likely held growth mindsets that allowed them to "quickly adapt to a new learning [and teaching] environment" (Pokhrel \& Chhetri, 2021, p. 135). Further research should be conducted on students' perspectives of ERT and on learning cultures of classrooms during Hyflex teaching, which is teaching online and face-to-face simultaneously. 


\section{References}

Australian Government Tertiary Education Quality and Standards Agency (TEQSA) (Nov 2020). Foundations for good practice: The student experience of online learning in Australian higher education during the COVID-19 pandemic [Report]. https://www.teqsa.gov.au/sites/default/files/student-experience-of-online-learning-in-australian-he-duringcovid-19.pdf?v=1606442611

Bhagat, S., \& Kim, D. J. (2020). Higher education amidst COVID-19: Challenges and silver lining. Information Systems Management, 37(4), 366-371. https://doi.org/10.1080/10580530.2020.1824040

de Boer, H. (2021). COVID-19 in Dutch higher education. Studies in Higher Education, 46(1), 96-106. https://doi.org/10.1080/03075079.2020.1859684

Campbell, J., Quincy, C., Osserman, J., \& Pedersen, O. (2013). Coding in-depth semi-structured interviews: Problems of unitization and intercoder reliability and agreement. Sociological Methods \& Research, 42(3), 294-320. https://doi.org/10.1177\%2F0049124113500475

Duggleby, W. (2005). What about focus group interaction data? Qualitative Health Research, 15(6), 832-840. https://doi.org/10.1177\%2F1049732304273916

Harris, R., Blundell-Birtill, P., \& Pownall, M. (2021). "A more personal way to learn during such an isolating time": The value of live lectures in online teaching. Student Success, 12(3), 113-117. https://doi.org/10.5204/ssj.1781

Hodges, C., Moore, S., Lockee, B., Trust, T., \& Bond, A. (2020, March 27). The difference between emergency remote teaching and online learning. Educause Review. https://er.educause.edu/articles/2020/3/the-difference-betweenemergency-remote-teaching-and-online-learning

Jung, J., Horta, H., \& Postiglione, G. A. (2021). Living in uncertainty: The COVID-19 pandemic and higher education in Hong Kong. Studies in Higher Education, 46(1), 107-120. https://doi.org/10.1080/03075079.2020.1859685

Kift, S., Zacharias, N., \& Brett, M. (2021). The best chance for all: A policy roadmap for post-pandemic panic. Student Success, 12(3), 26-36. https://doi.org/10.5204/ssj.1782

Lattuca, L. R. (2002). Learning interdisciplinarity: Sociocultural perspectives on academic work. The Journal of Higher Education, 73(6), 711-739. https://doi.org/10.1080/00221546.2002.11777178

Leask, B. (2020). Embracing the possibilities of disruption. Higher Education Research and Development, 39(7), 13881391. https://doi.org/10.1080/07294360.2020.1824211

Meskill, C. (2013). Introduction: Sociocultural perspectives. In C. Meskill (Ed.) Online teaching and learning: Sociocultural perspectives (pp. 1-17). Bloomsbury Publishing.

Miles, M., \& Huberman, A. (1994). Qualitative data analysis: An expanded sourcebook. Sage.

Pokhrel, S., \& Chhetri, R. (2021). A literature review on impact of COVID-19 pandemic on teaching and learning. Higher Education for the Future, 8(1), 133-141. https://doi.org/10.1177\%2F2347631120983481

Rapanta, C., Botturi, L., Goodyear, P., Guardia, L., \& Koole, M. (2020). Online university teaching during and after the Covid-19 crisis: Refocusing teacher presence and learning activity. Postdigital Science and Education, 2, 923-945. https://doi.org/10.1007/s42438-020-00155-y

Sagy, O., Kali, Y., Tsaushu, M., \& Tal, T. (2018). The culture of learning continuum: Promoting internal values in higher education. Studies in Higher Education, 43(3), 416-436. https://doi.org/10.1080/03075079.2016.1174205

Watermeyer, R., Crick, T., Knight, C., \& Goodall, J. (2020). COVID-19 and digital disruption in UK universities: Afflictions and affordances of emergency online migration. Higher Education, 81, 623-641. https://doi.org/10.1007/s10734-020-00561-y

Yang, B., \& Huang, C. (2021). Turn crisis into opportunity in response to COVID-19: Experience from a Chinese University and future prospects. Studies in Higher Education, 46(1), 121-132.

https://doi.org/10.1080/03075079.2020.1859687

\section{Please cite this article as:}

Mitchell, M., Gill, C., \& Brodmerkel, S. (2022). Academics' narratives of productive learning cultures during COVID-19 emergency remote teaching in Australia. Student Success, 13(1), 54-66. https://doi.org/10.5204/ssj.2146

This article has been peer reviewed and accepted for publication in Student Success. Please see the Editorial Policies under the 'About' section of the Journal website for further information.

Student Success: A journal exploring the experiences of students in tertiary education.

Except where otherwise noted, content in this journal is licensed under a Creative Commons Attribution 4.0 International Licence. As an open access journal, articles are free to use with proper attribution. ISSN: 2205-0795 